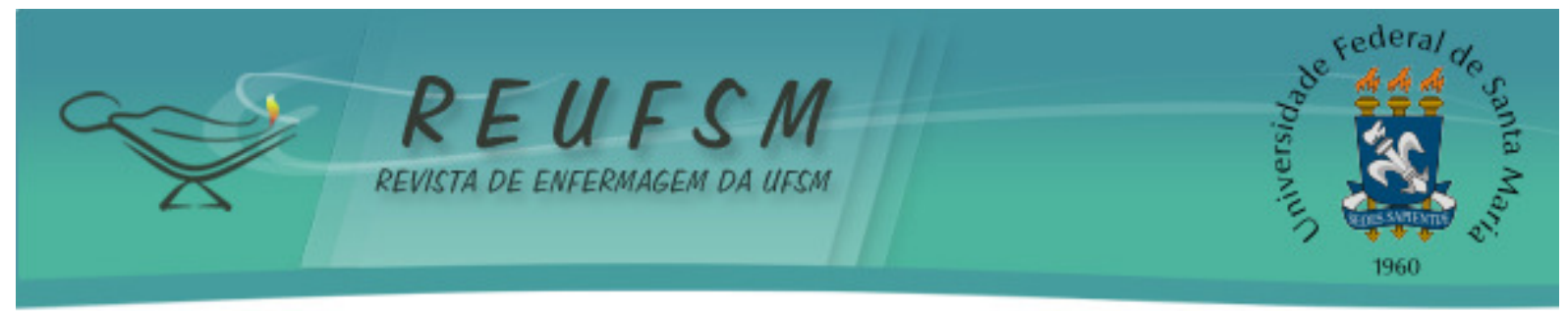

ARTIGO ORIGINAL

\title{
CONCEPÇÕES DE SAÚDE DE USUÁRIOS E PROFISSIONAIS DE UMA ESTRATÉGIA DE SAÚDE DA FAMÍLIA
}

CONCEPTIONS OF HEALTH FOR USERS AND PROFESSIONALS OF A FAMILY HEALTH STRATEGY CONCEPCIONES DE SALUD PARA USUARIOS Y PROFESIONALES DE UNA ESTRATEGIA
SALUD DE LA FAMILIA

Doi: $10.5902 / 2179769210461$

Maria de Lourdes Denardin Budó ${ }^{1}$

Maria Denise Schimith ${ }^{2}$

Raquel Pötter Garcia ${ }^{3}$ Margot Agathe Seiffert ${ }^{4}$

Bruna Sodré Simon ${ }^{5}$

Fernanda Machado da Silva ${ }^{6}$

RESUMO: Objetivo: conhecer as concepções de saúde dos usuários e profissionais de saúde inseridos em uma Estratégia de Saúde da Família, localizada em um município do sul do Brasil. Método: estudo descritivo, qualitativo, realizado com informantes-chave: seis moradores, seis agentes comunitários de saúde e sete dos demais integrantes da equipe de saúde da família. Para a coleta de dados utilizou-se a Estimativa Rápida Participativa, com fonte de dados da observação e entrevista. Os dados foram trabalhados pela análise temática. Resultados: a saúde foi apontada pelos informanteschave como condição para manutenção da vida, resultante da interação de fatores, de condições e hábitos de vida e sendo influenciada pela ocupação e pelas interações sociais. Conclusões: os profissionais devem envolver as questões sociais, ambientais e psicológicas no planejamento da assistência, já que essas foram reveladas de forma significativa como determinantes em saúde.

Descritores: Processo saúde-doença; Programa saúde da família; Enfermagem.

ABSTRACT: Aims: to identify the conceptions of health of users and health professionals of a Family Health Strategy located in a city of the south of Brazil. Methods: descriptive and qualitative study realized with key informants: six residents, six community health agents and seven other members of the family health team. For the data collection the Participatory Rapid Appraisal was used, with the observation and interview as data sources. A theme analysis was carrierd out with the data. Results: health was pointed out by the key informants as a condition for life maintenance, as a result of the interaction of

\footnotetext{
${ }^{1}$ Enfermeira. Doutora em Enfermagem. Professora Adjunta do Departamento de Enfermagem e do Programa de Pós-Graduação em Enfermagem (PPGEnf) da Universidade Federal de Santa Maria (UFSM). Santa Maria, RS, Brasil. Email: lourdesdenardin@gmail.com

${ }^{2}$ Enfermeira. Doutora em Ciências da Saúde. Professora Adjunta do Departamento de Enfermagem da UFSM. Santa Maria, RS, Brasil. Email: ma.denise2011@gmail.com

${ }^{3}$ Enfermeira. Mestre em Enfermagem. Doutoranda do Programa de Pós-Graduação em Enfermagem da Universidade Federal de Pelotas (UFPel). Bolsista da Coordenação de Aperfeiçoamento de Pessoal de Nível Superior (CAPES). Pelotas, RS, Brasil. E-mail: raquelpottergarcia@gmail.com

${ }^{4}$ Enfermeira. Professora Substituta do Departamento de Enfermagem da UFSM. Mestranda do PPGEnf da UFSM. Santa Maria, RS, Brasil. E-mail: margotenfer@gmail.com

${ }^{5}$ Enfermeira. Professora Substituta do Departamento de Enfermagem da UFSM. Mestranda do PPGEnf da UFSM. Bolsista CAPES. Santa Maria, RS, Brasil. E-mail: enf.brusimon@gmail.com

${ }^{6}$ Enfermeira. Mestre em Enfermagem. Professora Assistente do Curso de Enfermagem da Universidade Federal do Pampa (UNIPAMPA). Uruguaiana, RS, Brasil. E-mail: fernandadasi@yahoo.com.br
} 


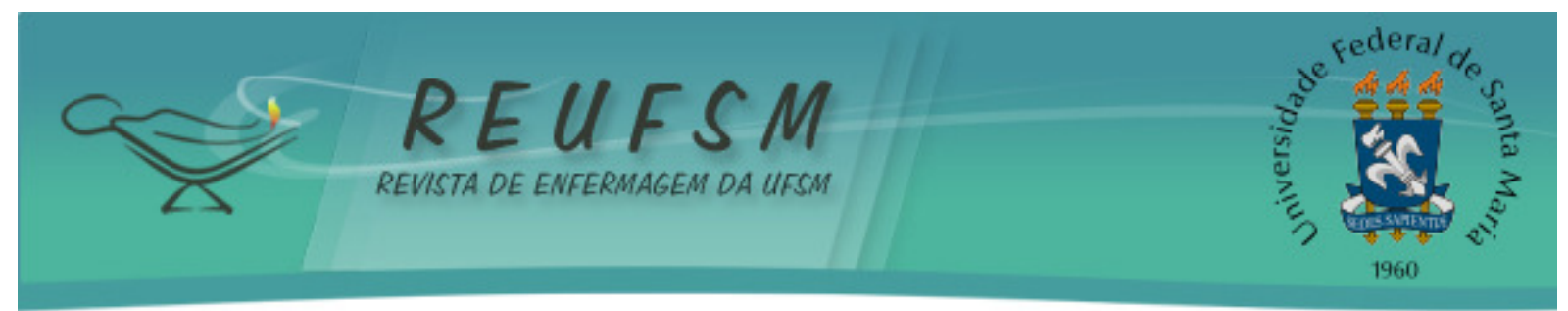

various aspects, conditions and lifestyle, influenced by occupation and social interactions. Conclusions: the professionals should involve social, environmental and psychological aspects in the planning of the assistance, since these significantly appeared to be determining in regards to health.

Descriptors: Health-disease process; Family health program; Nursing.

RESUMEN: Objetivo: conocer las concepciones de salud de usuarios y profesionales de salud incluídos en una Estrategia de Salud de la Familia, localizada en un municipio del sur de Brasil. Métodos: estudio descriptivo y cualitativo, realizado con informantes-clave: seis residentes, seis agentes comunitarios de salud y otros siete miembros del equipo de salud de la familia. Para recolectar datos se utilizó la Estimativa Rápida Participativa, con fuente de datos de observación y entrevista. Los datos fueron analizados mediante análisis temático. Resultados: la salud fue señalada por los informantes-clave como condición para mantenimiento de la vida, resultante de la interacción de factores, condiciones y hábitos de vida, siendo influenciada por ocupación e interacciones sociales. Conclusión: los profesionales deben considerar las cuestiones sociales, ambientales y psicológicas en la planificación de la asistencia, ya que estas se revelaron de manera significativa como determinantes para la salud.

Descriptores: Proceso salud-enfermedad; Programa de salud familiar; Enfermería.

\section{INTRODUÇÃO}

Há muitos anos a saúde tem sido compreendida como sinônimo da ausência de doença, tanto para a população, como para os profissionais da área. Os serviços de saúde privilegiam, em sua organização, uma atenção curativista ${ }^{1}$, na qual os trabalhadores concentram-se no aspecto biológico, não atentando aos demais determinantes do processo saúde/doença.

Essa visão reducionista frente o ser humano apresenta limitações desde meados do século XIX ${ }^{2}$, apontando para a necessidade de se construir uma nova concepção de saúde, a qual contemple a lacuna entre o campo conceitual, as práticas sanitárias e os reais problemas da população.

Nessa vertente, o conceito pioneiro de saúde foi estabelecido pela Organização Mundial de Saúde (OMS), na década de 40. Essa foi definida como o completo bem-estar físico, mental e social, e não a simples ausência de doença. ${ }^{3}$ Essa definição tornou-se um marco no campo da saúde mundial, pois sinalizou para a complexidade do tema e sobre a necessidade da reflexão ampliada a respeito de seu significado, assinalando para a busca de ações intersetoriais e interdisciplinares no sentido de proporcionar condições de vida saudáveis aos indivíduos. ${ }^{1}$ No entanto, esse conceito de saúde, proposto pela OMS, apresenta limitações no momento atual, pois o "completo bem-estar" seria apenas um ideal, não sendo de fato alcançado pelas pessoas.

Atualmente, a saúde é apontada como resultante das condições de vida, especialmente no que tange as condições econômicas, que permitem o acesso à saúde e às variadas dimensões da vida, como trabalho, educação e lazer. ${ }^{4}$ Essa concepção de saúde está relacionada com o conceito de promoção da saúde, o qual concebe-se como uma forma de interpretar as necessidades cotidianas de saúde da população em uma ótica coletiva e que compreende a saúde como produção social, considerando-se os determinantes socioeconômicos. ${ }^{5}$

Dessa maneira, observa-se que a conceituação de saúde amplia-se à medida que incorpora diferentes dimensões da vida humana, deixando de ser compreendida apenas como ausência de doença. Assim, para que ocorresse a consolidação e mudança desse 


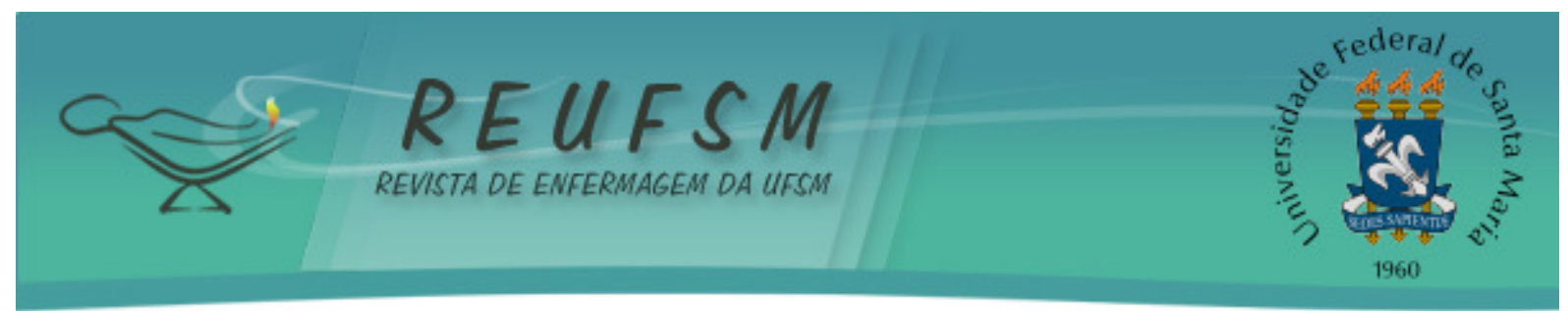

'paradigma' do conceito de saúde, fez-se necessário que usuários, profissionais e gestores "pudessem compreender e discutir os diversos entendimentos de saúde e seus desdobramentos sobre as políticas e práticas de saúde". 6:167 Nesse sentido, o campo da saúde vem delineando novos rumos e focos de atenção, partindo do pressuposto de que a compreensão da saúde apresenta-se como um processo dinâmico, multifacetado e social. ${ }^{7}$

Diante dessas considerações, elaborou-se a seguinte questão norteadora: quais as concepções de saúde de usuários e profissionais de saúde inseridos em uma Estratégia de Saúde da Família (ESF)? Dessa forma, o objetivo da pesquisa foi conhecer as concepções de saúde dos usuários e profissionais de saúde inseridos em uma ESF, localizada em um município do sul do Brasil.

A pesquisa foi realizada com os usuários e os profissionais da ESF para obter-se maior diversidade dos dados. A escolha pela ESF justifica-se por representar um cenário de cuidado a saúde que se encontra próximo a realidade dos indivíduos, possibilitando que as concepções de saúde sejam pautadas em suas vivências. Assim, a relevância desse estudo fundamenta-se na possibilidade de aproximação entre as diferentes concepções dos sujeitos envolvidos no processo saúde/doença/cuidado e, ainda, no fato de que poderão ser fornecidos subsídios para a elaboração de um planejamento contextualizado, o qual retrate as necessidades sentidas pelos atores envolvidos.

\section{MÉTODO}

Estudo qualitativo e descritivo, realizado com profissionais de saúde e com moradores de uma ESF de um município do sul do Brasil. Para a coleta de dados, utilizouse a Estimativa Rápida Participativa, que está fundamentada na identificação de informações relevantes, as quais exponham as verdadeiras condições locais, a partir da própria população. ${ }^{1}$ Foram utilizadas como fonte de dados, observação de campo e entrevistas com informantes-chave, que foram selecionados, intencionalmente, como pessoas de referência da comunidade. Desse modo, os critérios de seleção dos participantes da pesquisa foram: ter idade superior a 18 anos e ser profissional de saúde ou morador da área de abrangência da ESF.

A coleta de dados ocorreu de junho a novembro de 2008 e nas entrevistas buscouse questionar o entendimento sobre saúde e os fatores que interferem nela. As entrevistas ocorreram nas dependências da ESF e foram gravadas para posterior transcrição. Os dados foram submetidos à análise temática, que se constitui em descobrir os núcleos de sentido semelhantes que compõem uma comunicação. ${ }^{8}$

Fizeram parte da pesquisa 19 sujeitos, dentre eles, seis moradores da área de abrangência da ESF, seis Agentes Comunitários de Saúde (ACS) e sete integrantes da equipe de saúde. Os ACS entrevistados eram do sexo feminino e todos moravam há mais de dez anos na comunidade. Dentre os integrantes da equipe, participaram da entrevista dois técnicos em enfermagem, dois enfermeiros, uma médica, uma dentista e um auxiliar de consultório odontológico, representados por um homem e seis mulheres. Em relação aos moradores, quatro eram do sexo feminino e dois do masculino, sendo que todos relataram residir na comunidade há mais de 30 anos.

$\mathrm{Na}$ apresentação dos resultados as falas foram identificadas com código composto por uma ou duas letras e um número, como, por exemplo, MO1. As letras MO, EA e E representam, respectivamente, o morador, o ACS e a equipe de saúde. 0 número identifica a ordem da realização das entrevistas. Optou-se por agrupar os ACS separadamente do restante da equipe, mesmo fazendo parte dessa, uma vez que, além de atuarem como profissionais de saúde, estão inseridos na comunidade enquanto moradores dela. Assim, além da visão profissional, os ACS 


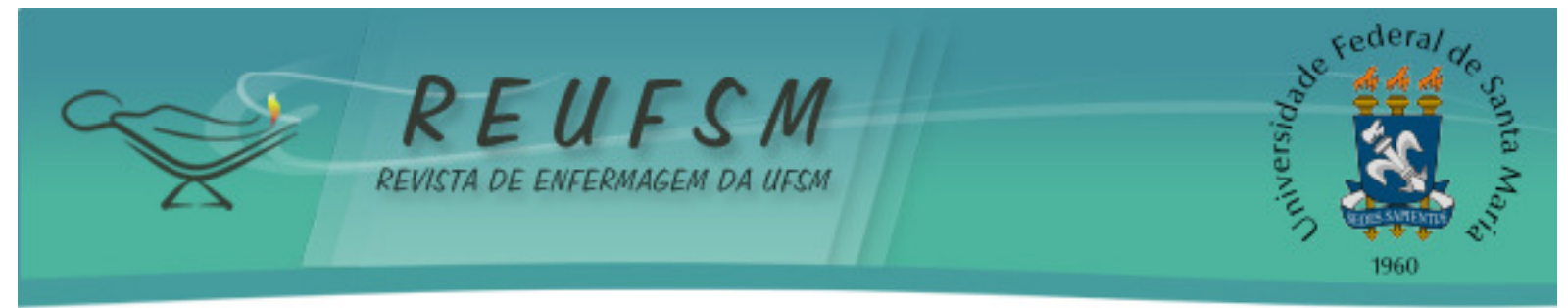

compartilham, com os demais moradores, do mesmo espaço geográfico, social e cultural, o que pode proporcionar diversidade nos depoimentos.

Foram respeitados os preceitos éticos de pesquisa com seres humanos, sendo o projeto analisado e aprovado pelo Comitê de Ética em Pesquisa da instituição na qual está vinculado, sob registro de número 0088.0.243.000-08.

\section{RESULTADOS E DISCUSSÃO}

A análise temática dos dados permitiu conhecer sete principais temas representativos das concepções de saúde dos informantes-chave. Dessa forma, a saúde foi relacionada: a manutenção da vida; a interação de fatores; a infraestrutura social e ambiental; as condições de vida; aos hábitos de vida; a ocupação; e, as interações sociais.

$\mathrm{Na}$ concepção de saúde como condição para a manutenção da vida, os informanteschave a apontam como primordial na vida das pessoas, caracterizada como elemento relevante para sua conservação.

É uma coisa muito importante [...] Porque a gente sem saúde não é ninguém. (MO4)

Ah! Saúde é o todo da pessoa [...] saúde para mim é tudo. (EA6)

Percebeu-se, nas falas dos entrevistados, que a saúde tem uma concepção ampla na vida dos sujeitos, refletindo em todos os setores de suas vidas, uma vez que, sem saúde, sentem-se impossibilitados de realizar suas atividades diárias. A saúde foi considerada como a totalidade do ser humano, primordial para a manutenção da vida.

Em estudo realizado com adolescentes, acerca da representação social sobre saúde, esses destacaram ideia similar, ao afirmar que a saúde se insere como algo relevante, sendo o alicerce para o desenvolvimento da vida. ${ }^{7}$ Ainda, outra pesquisa com usuários de uma ESF detectou que a saúde é condição para o desenvolvimento das atividades cotidianas, inerente ao processo de viver. ${ }^{4}$

Apesar de a saúde ser um bem precioso, não há, para ela, uma definição precisa nem estática, pois cada pessoa ou grupo pode modificar sua concepção ao longo da vida, de acordo com suas crenças ou contexto cultural. ${ }^{9}$ Assim, pode-se compreender o conceito de saúde de maneira singular. Logo, cada indivíduo desenvolve um conceito sobre ela a partir de suas experiências e de seu entendimento acerca da mesma.

Outra concepção encontrada é de que a saúde resulta da interação de fatores psicológicos, espirituais, emocionais e físicos.

Saúde para mim é mente, alma, corpo em sintonia, porque muitas doenças, acho que é assim, um pouco psicológico, tu colocas na cabeça e acontece mesmo [...]. Hoje em dia, eu acho que é muita preocupação [...] então são coisas que atingem muito a saúde [...]. (MO3)

[...] é a pessoa estar saudável físico e mental. É o lazer [...] o espiritual. (EA5) 


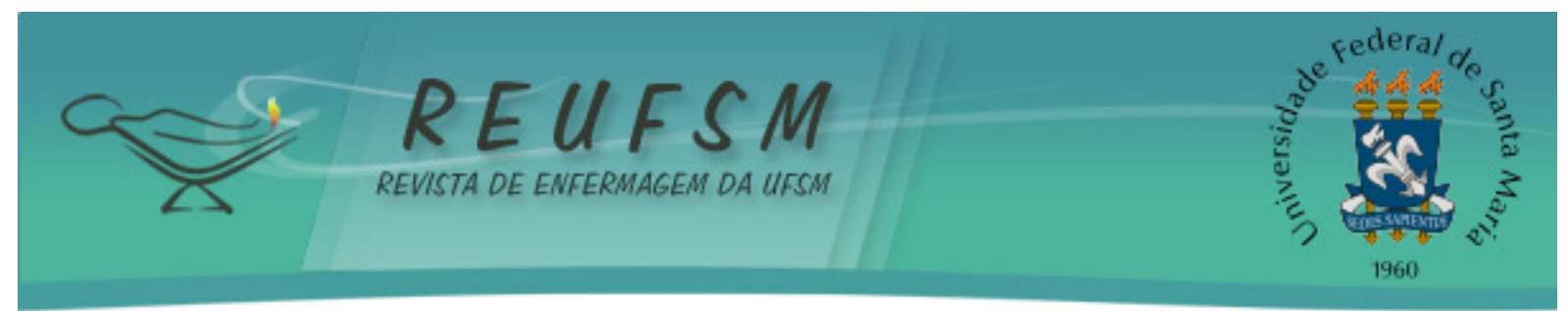

As falas dos informantes-chave referem que o ser humano não é visto de forma fragmentada, e sim integrado com o meio onde vive. Além disso, enfatizou-se a necessidade do equilíbrio entre corpo e mente.

Destaca-se que o processo saúde/doença construiu-se ao longo da história, já que, em períodos anteriores, tinha-se uma redução e fragmentação do ser humano, porém, no contexto atual, busca-se o subjetivo e o complexo para explicar a realidade por meio de modelos que considerem as relações estabelecidas no meio em que as pessoas vivem. ${ }^{10}$ Desse modo, vários fatores se agregam ao conceito de saúde e esse se amplia ${ }^{11}$, o que vai ao encontro dos achados deste estudo, no qual os sujeitos contemplam diversos atributos para explicar o que seria ter saúde e o que poderia influenciá-la.

Os profissionais da saúde também assinalam para a relação de saúde como equilíbrio de fatores, relacionando-a ao conceito da OMS, tanto de forma objetiva, quanto subjetiva.

Saúde, é como diz a Organização Mundial de Saúde, é um bem-estar físico, mental e todo o contexto geral [...] Não é só a ausência de doença. (E2)

[...] é o bem-estar físico, social, mental, espiritual, estar mais ou menos em equilíbrio entre esses fatores [...]. (E5)

Os profissionais entrevistados possuem uma visão de saúde previamente formada e, mesmo refletindo sobre o conceito de saúde pautado em suas vivências e realidades de atuação, têm como maior embasamento sua formação acadêmica, técnica e capacitação como profissional de saúde. Logo, embasaram-se no conceito da OMS, não ampliando sua visão para outros aspectos que influenciam a saúde das pessoas, como as condições de vida. Por outro lado, autores enfatizam a necessidade de vislumbrar o bem-estar físico e mental, não necessariamente completo, mas associado às condições sociais que proporcionem uma vida digna às pessoas. ${ }^{12}$

Outros informantes indicam a concepção de saúde em uma perspectiva de infraestrutura social e ambiental, destacando a importância do saneamento básico adequado e da participação da população na manutenção do ambiente.

Saúde é um esgoto fechado, conscientização da população a colocar lixo no devido lugar [...]. (EA3)

[...] é o saneamento básico, é uma rua, a água, iluminação pública [...]. (EA6)

A relação entre meio ambiente e saúde está sendo discutida desde a $8^{\mathrm{a}}$ Conferência Nacional de Saúde, em âmbito popular, porém, ultimamente, o cenário científico, por meio de pesquisas, tem se voltado, do mesmo modo, para essas questões. ${ }^{13-}$ ${ }^{14}$ Essa relação indica que o meio ambiente pode ser caracterizado tanto como a causa como a consequência dos determinantes de saúde ${ }^{14}$, fato detectado nas falas dos participantes do estudo e que se relaciona ao conceito de promoção da saúde, no qual os fatores ambientais, dentre outros, podem influenciar no bem-estar das pessoas.

Nessa perspectiva, é necessário que a sociedade possa usufruir do meio ambiente de forma moderada, com a adoção de hábitos menos poluentes a fim de alcançar sua manutenção e, consequentemente, gerar a redução dos danos à saúde. ${ }^{14}$ Para tanto, os profissionais de saúde, especialmente os ACS, por terem contato direto com a comunidade, 


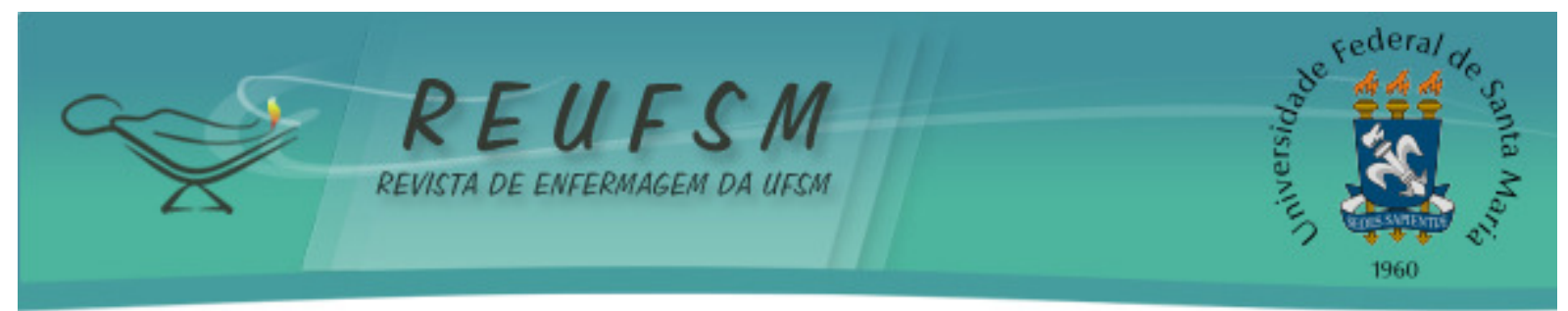

devem atentar para essa temática, com o objetivo de sensibilizar a população a respeito de sua importância e relevância para a promoção da saúde.

A concepção de saúde também foi atribuída à combinação de outros fatores, com destaque para as condições de vida.

Na saúde, acho que para começar a pessoa tem que ter um ganho, para dar ao menos o básico para a família, acho que dali já começa tudo. (MO1)

As condições de vida são determinantes para a saúde, influenciadas pelo fator renda. De acordo com os informantes, ter recursos financeiros possibilita acesso à alimentação, moradia, vestimenta e lazer, o que implica na saúde. Corroborando, um estudo constatou que a qualidade dos hábitos alimentares é influenciada pela renda dos indivíduos, o que, consequentemente, afeta nas condições de saúde da população ${ }^{15}$, incitando no modo em que ela vive.

Ainda, de uma forma objetiva, os informantes relacionam a falta de trabalho ou a dificuldade financeira como um fator contribuinte para o adoecimento e a precariedade da saúde. Desse modo, as condições financeiras são estabelecidas como determinantes para a geração e manutenção da saúde das populações. ${ }^{16}$

De acordo com os relatos, as condições de vida estão intimamente relacionadas ao fator renda. No entanto, alguns informantes chamam a atenção para o fato de que a renda deve proporcionar bem-estar e não apenas suprir as necessidades básicas, em uma perspectiva de promoção da saúde.

Saúde é a soma de diversos fatores, como alimentação, educação, cultura, lazer, família, amigos, diversão. Para que uma pessoa esteja saudável, ela tem que estar em equilíbrio, tem que ter um emprego, gostar dele, sentir-se valorizada e, claro, receber o que considera um salário justo. (E4)

Para os informantes, a renda das pessoas deve proporcionar condições de vida para além das necessidades básicas, deve permitir o acesso à educação, ao lazer e à diversão. A concepção de saúde, portanto, é relacionada à promoção da saúde.

A discussão sobre promoção da saúde tem como ponto de partida, o próprio conceito de saúde. Ao longo da história, várias concepções de saúde foram formuladas e reformuladas, a partir de configurações sociopolíticas específicas e do arcabouço de conhecimento disponível. ${ }^{17}$ Portanto, a evolução dessa concepção muda na dependência do conceito de saúde, tornando-se mais abrangente na medida em que se amplia a compreensão acerca do processo saúde/doença da humanidade. Avança-se, assim, de uma concepção pautada nas mudanças de hábitos de vida e comportamentos para uma compreensão de que a promoção da saúde depende das condições de vida ${ }^{5}$, bem como o entendimento do que é saúde.

Assim, pode-se afirmar que alguns informantes possuem uma visão ampliada de saúde e uma visão subjetiva, a qual abrange, em suas raízes, aspectos positivos de entender o que é a saúde, superando a conceituação de somente ausência de doença. Esses resultados vão ao encontro de uma pesquisa realizada com enfermeiros, em que eles demonstraram um entendimento abrangente sobre o conceito de saúde, sendo essa influenciada por determinantes físicos, psicossociais e socioeconômicos. ${ }^{18} \mathrm{Tal}$ conceito de saúde favorece a reflexão sobre o processo de sua produção, exigindo a compreensão de 


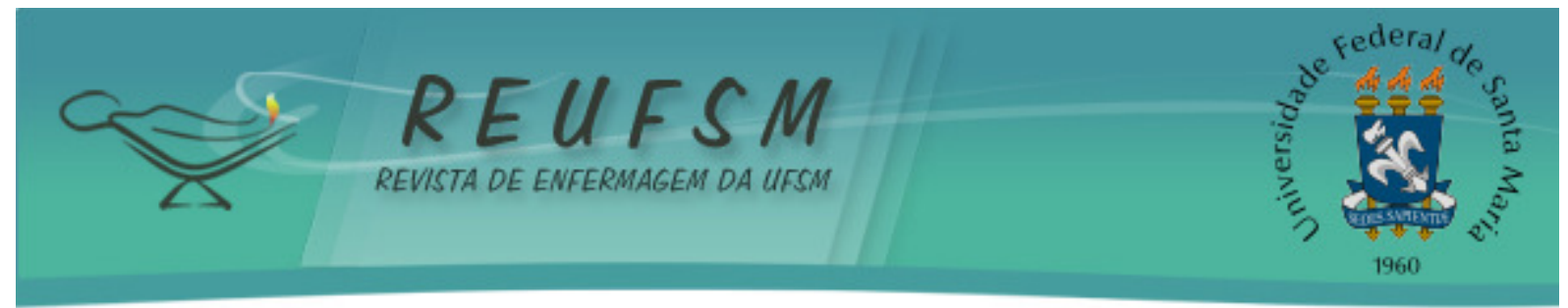

atividades interdisciplinares e práticas intersetoriais, bem como o desenvolvimento de ações que auxiliem na produção de saúde. ${ }^{17}$

Os informantes relacionaram a concepção de saúde como resultante dos hábitos de vida, principalmente, em relação à alimentação inadequada, ao tabagismo, à drogadição e ao consumo de bebidas alcoólicas.

[...] o que interfere na saúde das pessoas, no meu ponto de vista, é o seguinte: é o cigarro, a droga, a bebida [...]. (MO5)

Acho que vai de uma boa alimentação e a pessoa saber se cuidar [...] têm pessoas que fumam e bebem demais [...] abusam da saúde, daí não pode ter uma saúde boa. Até comer demais, se alimentar demais faz mal. (MO6)

O acesso à alimentação, conforme já abordado, pode ser determinado pelas condições socioeconômicas, porém os informantes destacam que os hábitos alimentares nem sempre estão relacionados a esse fator, mas pelas escolhas de vida, as quais podem ser influenciadas pelo contexto sociocultural das pessoas. Assim, os entrevistados apontam para a complexidade do entendimento acerca da saúde e doença.

Destaca-se que não se deve avaliar a má saúde de uma população como resultado somente de sua cultura, mas considerar sua situação econômica e social, sem responsabilização unicamente individual. ${ }^{19}$ A saúde apresenta-se como um conceito inerente ao indivíduo e sua relação com a ordem social ${ }^{7}$, tornando relevante todas as características que permeiam as pessoas, a fim de se detectar as questões que se encontram fora de sua possibilidade de ação.

Em outro depoimento, é defendido que a saúde está associada às orientações e informações adequadas, as quais subsidiam as práticas de vida:

[...] Conheço pessoas que têm dinheiro e comem errado, eu digo: vocês comem tudo errado e não têm saúde, têm pressão alta, depressão, diabetes, comem tudo que não é para comer. o que falta? Falta ter pessoas que orientem essas pessoas para não fazer isso [...]. (MO6)

Segundo os dados, os hábitos de vida, em especial, os chamados "prejudiciais" para a saúde, podem ser modificados com o auxílio de orientações dos profissionais de saúde por meio das práticas de educação em saúde. Essas devem ser guiadas por princípios democráticos e de participação cidadã, de forma que se respeitem as escolhas e o conhecimento dos usuários, ultrapassando a orientação unidirecional, promovendo uma atitude de reflexão sobre as possibilidades adequadas ao contexto dos sujeitos. ${ }^{20}$

É preciso que essas informações sejam convergentes com a realidade das pessoas assistidas, bem como compartilhadas com uma linguagem acessível. Assim, as ações de educação em saúde precisam ter um planejamento "com os sujeitos e não para os sujeitos" "21:2287, de modo que os usuários dos serviços se reconheçam como corresponsáveis pela sua saúde.

Outro informante-chave cita, como condicionante à saúde, o seguimento dessas orientações, em uma concepção vertical. 


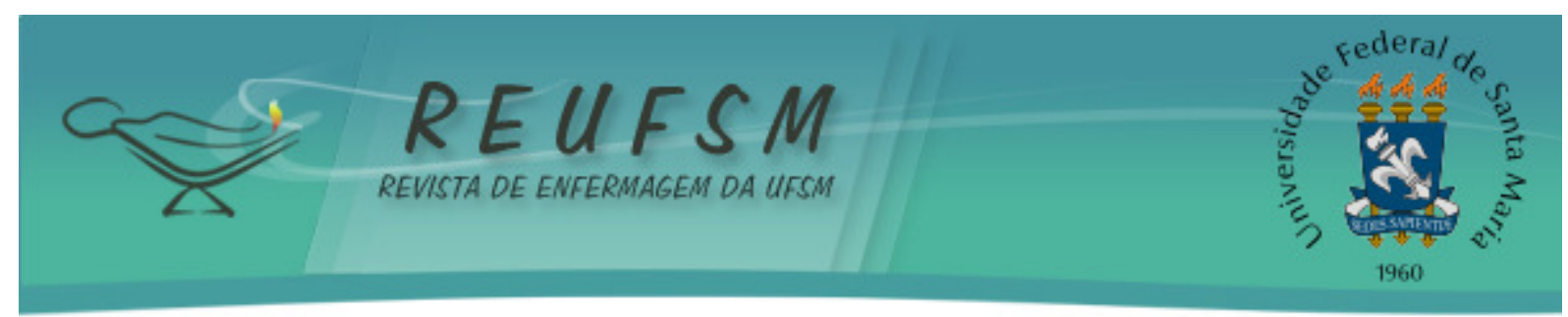

[...] se todos fizessem o tratamento como o médico manda, porque se não for aquilo ali que o médico manda, eles não ajudam, não adianta. (EA3)

O depoimento do profissional de saúde revela uma visão de saúde pautada no modelo biomédico, centrada na figura do profissional de saúde como detentor da verdade e disseminador das informações, enquanto que os usuários são considerados receptores acríticos. Tal situação foi encontrada em outras pesquisas ${ }^{11,16}$, as quais detectaram uma visão centrada no biológico e na qual a saúde estaria circunscrita à presença do médico e do medicamento.

Diante disso, mesmo que exista um movimento de mudança de paradigma na saúde, principalmente em relação ao seu conceito, alguns profissionais de saúde sustentam uma visão simplificada das pessoas. Esses reproduzem, de certa forma, o modelo biomédico por meio da condução de práticas para "escolhas saudáveis", as quais promovam o manejo da saúde.

A ocupação também foi mencionada como sinônimo de saúde pelos informanteschave, em uma perspectiva de sentir-se útil.

[...] Não fico parada, faço crochê, pinto, costuro. Só agora, depois que piorei mesmo, aí não costurei, costurei muito pouco [...] $e$ agora ando louca para costurar [...] Trabalhei bastante, ajudei meu marido, porque eu costurava para fora, me aposentei costurando. (MO4)

A realização de atividades laborais é considerada como um fator importante para a saúde. Nota-se, então, que a saúde pode ser ou não adquirida, a partir do momento que o sujeito se encontra ocupado, dando sentido a sua vida a partir do trabalho. Logo, ter saúde tem relação com a vitalidade e a capacidade de executar alguma função na sociedade. ${ }^{16}$ Outros autores ressaltam que, além do corpo ser visto como um meio de produção, que necessita estar sadio para o pleno desenvolvimento do trabalho, sentir-se útil e produtivo proporciona às pessoas, igualmente, bem-estar. ${ }^{22}$

Ainda, os informantes da pesquisa relataram que a saúde é influenciada pelas interações sociais, as quais proporcionam bem-estar.

[...] é o bem-estar até da pessoa [...] estar bem, participar de grupos, estar assim sorrindo, isso para mim é saúde. (EA2)

Olha, acho que seria melhor se tivesse um espaço físico para fazer caminhada, lazer, uma praça de recreação para os pais virem com os filhos, jogar futebol. Acho que o que está faltando é isso para os problemas de saúde. Falta um lugar para as pessoas irem, se encontrarem, conversarem. (EA1)

Além da função produtiva na sociedade, os informantes salientaram que as pessoas necessitam de momentos e lugares apropriados para se relacionarem uns com os outros. Nesse contexto, a interação social foi compreendia como um determinante benéfico para a saúde. A participação em projetos sociais, bem como de práticas de atividades físicas, possibilita que os indivíduos desenvolvam relações que podem auxiliar na reabilitação de sua saúde. ${ }^{23}$ 


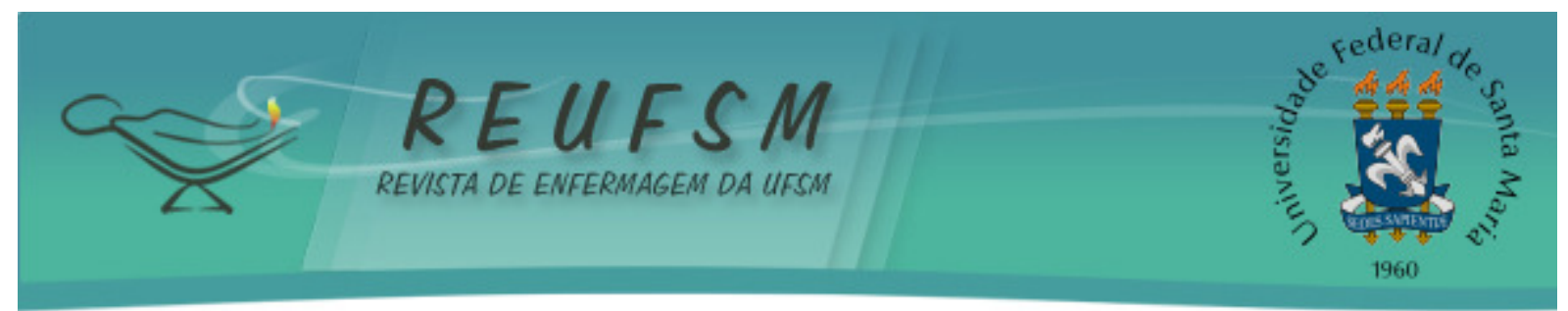

Os dados também mostram que a falta de locais de lazer atua de modo negativo na saúde. Confirmando esses achados, pesquisa revelou que a saúde dos moradores da área de uma ESF torna-se prejudicada pela falta de estrutura física no território da comunidade, impedindo a prática de atividades esportivas e culturais. ${ }^{24}$ Essa falta de locais apropriados para atividades físicas e de lazer pode dificultar até mesmo a realização de grupos de caminhada, que conforme estudo realizado com mulheres hipertensas, representa uma ação de baixo custo, tendo potencialidade para ser implementada em ESF, além de auxiliar na prevenção de doenças. ${ }^{25}$

\section{CONCLUSÃO}

Ao analisar as concepções de saúde dos usuários e profissionais da ESF estudada, observou-se que há uma variedade de entendimentos sobre essa temática. Dentre eles, pode-se destacar uma visão ampla sobre a saúde, com predomínio de uma perspectiva de equilíbrio e combinação de vários determinantes ou sua condição de essencialidade para a vida.

Para alguns profissionais da saúde, os quais sofrem a influência da formação acadêmica, a saúde foi concebida com as ideias e preceitos da OMS. Assim, observa-se que muitas condutas assistenciais da equipe de saúde são reflexos de seu modo de pensar, o qual é coerente com a formação profissional de cada sujeito. Tal formação, até hoje, tem influência do modelo biomédico e esse fato pode ser considerado uma limitação do estudo, pois as falas podem retratar o que os profissionais estão habituados a replicar verbalmente e não aquilo que realmente traduza o seu pensamento acerca da temática.

Ainda, constatou-se que as vivências permearam as falas dos sujeitos, o que pode servir de referência para as equipes de saúde, bem como para os gestores do Sistema Único de Saúde.

Diante disso, pretende-se que os resultados desse estudo possam instigar uma reflexão aos profissionais de saúde sobre como estão realizando as práticas de saúde. Além disso, sugestiona-se que os profissionais, dentre eles os enfermeiros, envolvam as questões sociais, ambientais e psicológicas no planejamento da assistência, já que essas foram reveladas, de forma significativa, como determinantes em saúde pelos moradores e ACS. Assim, a potencialidade do estudo encontra-se na possibilidade dos profissionais planejarem suas ações de acordo com as necessidades de saúde apontadas pelos sujeitos.

Ademais, o estudo permitiu conhecer as diferentes concepções de saúde das pessoas envolvidas no processo saúde-doença, apresentando-se como relevante para o conhecimento na área da temática pesquisada.

\section{REFERÊNCIAS}

1. Tancredi FB, Barrios SRL, Ferreira JHG. Planejamento em saúde. São Paulo: Universidade de São Paulo, Faculdade de Saúde Pública; 1998. 82 p. (vol. 2).

2. Siqueira KM, Barbosa MA, Brasil VV, Oliveira LMC, Andraus LMS. Crenças populares referentes à saúde: apropriação de saberes sócio-culturais. Texto \& Contexto Enferm. 2006;15(1):68-73.

3. World Health Organization. Carta de Ottawa. In: Ministério da Saúde (BR). Promoção da saúde: Cartas de Ottawa, Adelaide, Sundsvall e Santa Fé de Bogotá. Brasília (DF): Ministério da Saúde/FIOCRUZ; 1986.

4. Fertonani HP, Pires D. Concepção de saúde de usuários da Estratégia Saúde da Família e novo modelo assistencial. Enferm Foco. 2010;1(2):51-4. 


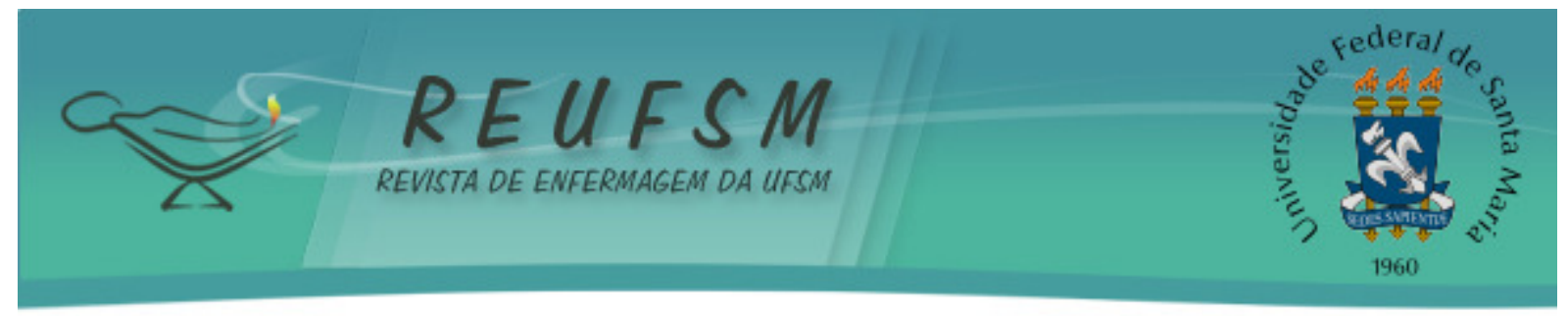

5. Rodrigues CC, Ribeiro KSQS. Promoção da saúde: a concepção dos profissionais de uma Unidade de Saúde da Família. Trab Educ Saúde. 2012 jul/out;10(2):235-55.

6. Wendhausen ALP, Rodrigues I. Concepções de saúde de conselheiros municipais de saúde da região da AMFRI/SC e a relação com a prática no conselho. Ciênc Cuid Saude. 2006;5(2):166-74.

7. Reis AT, Oliveira DC, Gomes AMT. Representações sociais sobre saúde entre adolescentes de escolas públicas do município do Rio de Janeiro. Rev Enferm UERJ. 2009 out/dez;17(4):473-8.

8. Minayo MCS. O desafio do conhecimento: pesquisa qualitativa em saúde. $11^{\text {a }}$ ed. São Paulo: Hucitec; 2010.

9. Herrera EM, Posada MLA. Creencias y prácticas em el cuidado de la saúde. Av Enferm. 2008;26(1):112-23.

10. Backes MTS, Rosa LM, Fernandes GCM, Becker SG, Meirelles BHS, Santos SMA. Conceitos de saúde e doença ao longo da história sob o olhar epidemiológico e antropológico. Rev Enferm UERJ. 2009 jan/mar;17(1):111-7.

11. Ferri SMN, Pereira MJB, Mishima SM, Caccia-Bava MCG, Almeida MCP. As tecnologias leves como geradoras de satisfação em usuários de uma unidade de saúde da família. Interface Comun Saúde Educ. 2007 set/dez;11(23):515-29.

12. Araújo AA, Brito AM, Novaes M. Saúde e autonomia: novos conceitos são necessários? Rev Bioética. 2008;16(1):117-24.

13. Camponogara S, Viero CM, Sari V, Erthal G. A abordagem da interface saúde e meio ambiente na formação profissional de enfermeiros. Rev Gaúch Enferm. 2011;32(4):647-53.

14. Camponogara S, Soares SGA, Viero CM, Erthal G, Diaz OS, Peres RR, et al. Responsabilidade ambiental na visão de acadêmicos da área da saúde. Rev Enferm UERJ. $2012 \mathrm{jan} / \mathrm{mar} ; 20(1): 39-44$.

15. Zart VB, Aerts D, Rosa C, Béria JU, Raymann BW, Gigante PL et al. Cuidados alimentares e fatores associados em Canoas, RS, Brasil. Epidemiol Serv Saúde. 2010 $\mathrm{abr} /$ jun;19(2):143-54.

16. Budó MLD, Mattioni FC, Machado TM, Ressel LB, Borges ZN. Concepções de violência e práticas de cuidado dos usuários da estratégia de saúde da família: uma perspectiva cultural. Texto \& Contexto Enferm. 2007 jul/set;16(3):511-9.

17. Arantes RC, Martins JLA, Lima MF, Rocha RNM, Silva RC, Villela WV. Processo saúdedoença e promoção da saúde: aspectos históricos e conceituais. Rev APS. 2008 abr/jun;11(2):189-98.

18. Degani GC, Camelo SHH. Percepções dos enfermeiros de Unidades de Saúde da Família sobre o processo saúde-doença. Cienc Cuid Saúde. 2009 abr/jun;8(2):213-9.

19. Helman CG. Introdução: a abrangência da antropologia médica. In: Helman CG. Cultura, saúde e doença. $5^{a}$ ed. Porto Alegre: Artmed; 2009. p. 11-25.

20. Vidal ECF, Saraiva KRO, Dodt RCM, Vieira NFC, Barroso MGT. Democracia e participação cidadã: um debate sobre as práticas de educação em saúde. Rev Gaúch Enferm. 2008 set;29(3):475-80.

21. Ebling SBD, Falkembach EM, Silva MM, Silva SO. Popular education and health education: a necessary link in health practices. Rev Enferm UFPE on line [Internet]. 2012 


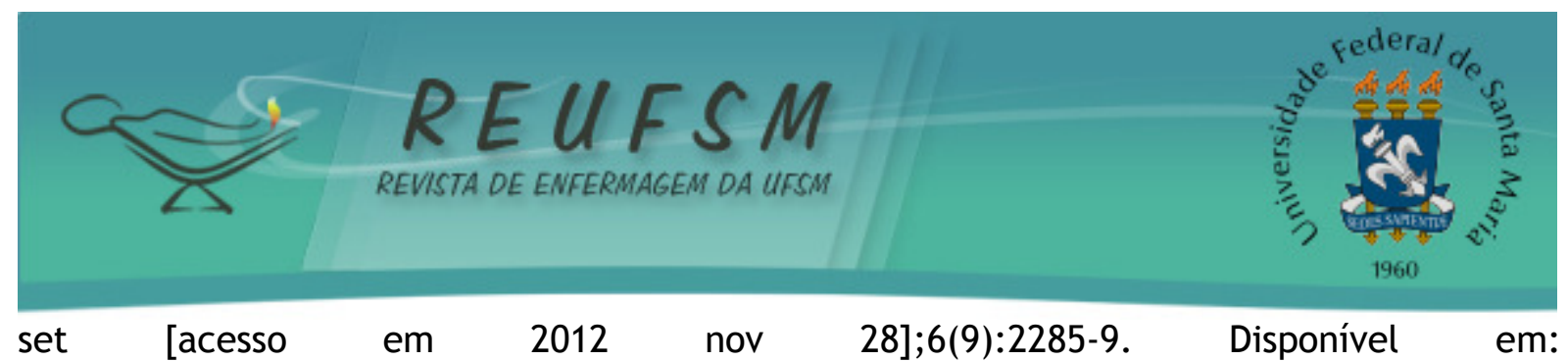

http://www.revista.ufpe.br/revistaenfermagem/index.php/revista/article/view/2584/pdf -1471.

22. Gomes LOS, Aguiar MGG. Programa de Saúde da Família: um espaço de reconstrução das representações sociais do processo saúde-doença? Rev Bras Enferm. 2006 set/out;59(5):614-9.

23. Silva PCS, Terra RS, Graciano ADS, Magalhães ECR, Santos WAL. Elderly people practicing physical activity in social projects and life satisfaction. Rev Enferm UFPE on line [Internet]. $2012 \mathrm{fev}$ [acesso em 2012 nov 28];6(2):409-16. Disponível em: http://www.revista.ufpe.br/revistaenfermagem/index.php/revista/article/view/2231/pdf 818 .

24. Mattioni FC, Budó MLD, Danieli GC. Practice of health education in the perspective of problematization living conditions of a community. Rev Enferm UFPE on line [Internet]. $2010 \mathrm{mai} / \mathrm{jun}$ [acesso em 2012 nov 12];4 Esp:1308-14. Disponível em: http://www.revista.ufpe.br/revistaenfermagem/index.php/revista/article/view/1095/pdf -118.

25. Silva LF, Silva EAM, Moreira RC, Mantovani MF. Grupo de caminhada: fator de proteção para eventos cardiovasculares em mulheres hipertensas. Rev Enferm UFSM [Internet]. 2012 maio/ago [acesso em 2013 ago 22];2(2):222-31. Disponível em:http://cascavel.ufsm.br/revistas/ojs-

2.2.2/index.php/reufsm/article/view/5473/3746.

Data de recebimento: $21 / 08 / 2013$

Data de aceite: $30 / 01 / 2014$

Contato com autor responsável: Maria de Lourdes Denardin Budó

Endereço postal: Universidade Federal de Santa Maria. Centro de Ciências da Saúde. Departamento de Enfermagem. Av Roraima, n¹000. Cidade Universitária. Bairro Camobi. CEP: 97105-900. Santa Maria, RS, Brasil.

E-mail: lourdesdenardin@gmail.com 